\title{
A CONSTRUÇÃO DA IDENTIDADE NEGRA NO ESPAÇO ESCOLAR: PERCEPÇÕES E DISCUSSÕES
}

\author{
CONSTRUCTION OF BLACK IDENTITY IN SCHOOL SPACE: PERCEPTIONS AND \\ DISCUSSIONS
}

Kellison Lima Cavalcante ${ }^{1}$

\begin{abstract}
Resumo: A construção identitária no espaço escolar é desenvolvida pelas relações entre todos os indivíduos que fazem parte do ambiente, constituindo um processo coletivo. Assim, a construção da identidade negra dos estudantes reflete diferentes relações sociais encontradas no espaço escolar, percorrendo conflitos, reconhecimentos, ações e participações dos estudantes no debate e discussão. O problema surge a partir das descobertas e conflitos vivenciados por jovens adolescentes no espaço escolar, onde eles constroem suas identidades e são constantemente colocados a prova dos limites da diferenciação da sociedade em que vivemos. Nesse sentido, esse trabalho tem como objetivo proporcionar a discussão sobre a construção da identidade negra no espaço escolar, a partir de uma abordagem descritiva no sentido do liame entre a relação da identidade e as relações sociais estabelecidas no espaço escolar. A pesquisa foi desenvolvida através de uma pesquisa bibliográfica e estudos exploratórios em busca de ampliar e fundamentar a análise do tema em discussão. Dessa forma, o espaço escolar, através de práticas socializadoras tem a capacidade de engajar os jovens no debate e reflexão crítica para um processo de reconhecimento de sua identidade racial.
\end{abstract}

Palavras-chave: Identidade Negra. Afrodescendência. Espaço Escolar.

\begin{abstract}
The identity construction in the school space is developed by the relations between all individuals that are part of the environment, constituting a collective process. Thus, the construction of the black identity of students reflects different social relationships found in the school space, covering conflicts, recognitions, actions and participation of students in debate and discussion. The problem arises from the discoveries and conflicts experienced by young adolescents in the school space, where they build their identities and are constantly put to the test of the limits of the differentiation of the society in which we live. In this sense, this work aims to provide the discussion about the construction of black identity in the school space, from a descriptive approach towards the link between the identity relationship and the social relations established in the school space. The research was developed through a bibliographical research and exploratory studies in order to broaden and substantiate the analysis of the subject under discussion. Thus, the school space, through socializing practices has the ability to engage young people in debate and critical reflection for a process of recognition of their racial identity.
\end{abstract}

Keywords: Black Identity. Africandescent. School space.

\footnotetext{
${ }^{1}$ Licenciado em Filosofia (UFPI), Especialista em Filosofia Contemporânea (Faculdade Souza) e Mestre em Tecnologia Ambiental (ITEP), e-mail: kellison.cavalcante@ifsertão-pe.edu.br.
} 


\section{INTRODUÇÃO}

O processo de colonização europeu de nossa sociedade e todo o processo histórico de reconhecimento da contribuição do negro permeia acontecimentos de intolerância e racismo, resultando em matrizes de segregação e difusão do racismo, do preconceito e da diferenciação pela cor da pele. De fato, historicamente, não é possível negar toda a ignorância e negação da valorização da condição do negro na formação de nossa sociedade. No entanto, é possível mostrar perspectivas, ampliar discussões e resgatar o processo de contribuição do negro na formação de nossa identidade, trazendo suas riquezas culturais, de luta e sobrevivência.

Nesse sentido, o espaço escolar consiste no lugar de socialização, discussão e esclarecimentos no processo de construção das identidades dos jovens estudantes. Sendo essa construção envolvida em todo o processo educativo, podendo ocorrer manifestações de conflito, como o racismo, a segregação dos jovens e consequentemente as negações de identidades.

De acordo com Guirado (1998), o espaço escolar consiste em um ambiente rico para aprendizagens e converte-se em espaço de conflitos e exclusões que são naturalizadas em seu cotidiano pelas práticas sociais. Assim, os estereótipos ou até mesmo representações da identidade negra podem influenciar no desenvolvimento pessoal, social e educacional dos jovens.

No entanto, a construção identitária do negro não é uma ação individual, e sim um processo coletivo. Dessa forma, esse processo de construção identitária no espaço escolar é desenvolvido pelas relações entre alunos, alunos e professores, e todas as interações sociais que contribuem para a formação social dos estudantes na comunidade escolar. Conforme Mizael e Gonçalves (2015), pensar a construção da identidade dos sujeitos é algo bastante complexo, pois os seres humanos são submetidos a constantes interações sociais, que os formam no que diz respeito a sentimentos, ações, ideologias, pensamentos etc. Assim, essas experiências da realidade da forma coletiva e individual permitem a compreensão de comportamentos nos vários espaços sociais.

Assim, a construção da identidade negra dos estudantes reflete diferentes relações sociais encontradas no espaço escolar. Torna-se fundamental e necessário o conhecimento do processo de construção dessa identidade, resultado das relações sociais e levadas para o espaço escolar, que possam ser trabalhadas a diversidade cultural, étnica e social da nossa sociedade.

O problema surge a partir das descobertas e conflitos vivenciados por jovens adolescentes no espaço escolar de ensino médio, onde eles constroem suas identidades e são constantemente colocados a prova dos limites da diferenciação da sociedade em que vivemos, sejam no cotidiano 
escolar, familiar e social. Dessa forma, essa identidade precisa ser compreendida e significada em relação ao que eles vivenciam no cotidiano escolar. Diante do multiculturalismo, surgem os questionamentos de como os jovens discentes constroem suas identidades negras nos espaços escolares? Como a educação contribui para reconhecimento da cultura e valores negros na sociedade atual?

A razão para o desenvolvimento desse trabalho é discutir como ocorre o processo de construção da identidade negra dos estudantes no espaço escolar. Onde é possível observar as manifestações e ações em busca de uma identidade e de afirmação na sociedade. Bem como as interferências e contribuições das relações sociais que ocorrem no espaço escolar no processo de identidade dos jovens, o que de fato o espaço escolar propicia para fomentar ações e práticas pedagógicas para a construção da identidade negra. 


\section{PRESSUPOSTOS METODOLÓGICOS}

A pesquisa se fundamenta no método dialético com foco na abordagem da discussão da construção da identidade negra e as relações sociais no espaço escolar. Utilizou-se uma abordagem descritiva, bem como do caráter bibliográfico, no sentido de compreender o processo de formação identitária dos jovens no processo de ensino-aprendizagem no espaço escolar.

Nesse sentido, a pesquisa é delineada a partir de uma pesquisa bibliográfica. Gil (2008) ressalta que a pesquisa bibliográfica parte dos estudos exploratórios em busca de ampliar e fundamentar a análise do tema em discussão, com a realização de pesquisas desenvolvidas a partir da técnica de análise de conteúdos. Dessa forma, as fontes secundárias foram obtidas através de consultas em bases de dados disponibilizadas no Portal Periódicos Capes, como SciELO, Scopus e Google Academic, através dos indexadores de identidade negra, espaço escolar e afrodescendência. Para a análise e discussão, a pesquisa baseou-se nas técnicas de investigação e redação filosófica propostas por Cunha (2013), que destaca a leitura analógica e analítica de textos filosóficos. 


\section{A IDENTIDADE NEGRA E O ESPAÇO ESCOLAR}

De acordo com Foulcault (1999) o Estado tem a escola como um instrumento de controle social e um dos aparelhos ideológicos do mesmo Estado. Assim, a escola e o seu espaço escolar, de convívio e de diferentes relações sociais, constituem papel importante na construção identitária dos discentes.

Oliveira (2016) observa que no espaço escolar ocorrem diferentes relações sociais e que estas refletem a diversidade cultural da sociedade brasileira. Dessa forma, o espaço escolar tornase primordial para a preparação dos discentes para o reconhecimento dos valores, costumes e contribuições da cultura negra na formação da sociedade brasileira em um constante processo de construção da identidade negra. Ainda de acordo com Oliveira (2016) através de uma boa educação é possível quebrar o preconceito racial contra os negros e deixá-los ser eles mesmos, expondo suas culturas, religiões, usando de seus direitos como todo cidadão brasileiro, onde estiver, pois são livres, não importando a cor da pele.

Nesse sentido, Fazzi (2006) ressalta que:

[...] a socialização entre pares constitui um espaço e tempo privilegiados em que crenças e noções raciais já aprendidas são experimentadas e testadas pelas crianças. E, nessas interações entre si, as crianças vão aprendendo o que significa ser de uma categoria racial ou de outra, criando e recriando o significado social de raça. Observou-se, então, uma espécie de jogo da classificação e autoclassificação raciais, no qual se estabelece um processo de negociação, manipulação e disputa para não ser identificado como um exemplar da categoria preto/negro. Esse jogo se intensifica devido ao reconhecimento da existência de um sistema categorial múltiplo no Brasil. O grande drama desse jogo é a negatividade associada à categoria preto/negro, que expõe as crianças nela classificadas a um permanente ritual de inferiorização, em que são especialmente atingidas por gozações e xingamentos (p. 218).

Assim, surge a necessidade da discussão e compreensão da temática, como forma de contribuir para o processo de escolarização dos jovens. Torna-se relevante o processo de socialização e de inserção de todos os envolvidos no ambiente escolar, com a finalidade de aproximar e abranger uma discussão integradora.

As constantes interações e modificações das relações sociais no mundo contemporâneo tornam o processo de construção da identidade negra como um complexo de ações, pensamentos e ideologias necessários para o desenvolvimento social dos discentes. Dessa forma, esse processo de identidade evidencia a importância do estudo no espaço escolar. De acordo com Souza e Gomes (2017) a questão da identidade negra do adolescente no contexto escolar é algo que chama a atenção e que merece ser estudado, tendo em vista a importância disso na formação deste indivíduo para que seja sujeito e protagonista de sua própria história. 
Nesse sentido, a escola torna-se um ambiente propício para o debate e discussão, possibilitando o reconhecimento da identidade negra. Assim, Bastos (2015) ressalta que:

\begin{abstract}
A escola é um lugar privilegiado no complexo devir da construção de identidades. Os diferentes sujeitos envolvidos no processo educativo desencadeado por instituições de ensino - professores, professoras, alunos, alunas e responsáveis - constroem diferentes identidades ao longo de sua história de vida, e a escola, como espaço de aprendizagem e socialização, tem grande importância nisso. Nesse sentido, o reforço de estereótipos e representações negativas do que é ser mulher e ser negro/a marca as trajetórias escolares dos sujeitos que desenvolvem diferentes estratégias para lidar com o preconceito, o racismo e o sexismo. É na escola que ocorre um dos mais marcantes confrontos de pertencimentos, e é neste território, para além da família, que as identidades de gênero e raça são também construídas (p. 616).
\end{abstract}

O espaço escolar, a partir de suas práticas socializadoras, tem a capacidade de incluir e excluir o jovem negro na sociedade atual. Para isso, o espaço escolar tem grande relevância na construção de embates e no reconhecimento da cultura negra em suas diferenças. Assim, o estudante negro passa e vivencia vários momentos importantes no espaço escolar, onde é possível destacar importantes experiências na definição de sua identidade.

Dessa forma, segundo Souza e Gomes (2017), pode-se dizer que a escola exemplifica a construção dinâmica da identidade, já que possui padrões de identificação e de atuação entre os indivíduos, mas também deve levar em conta algumas particularidades deles. Como Souza (1991) afirma que a formação da identidade do sujeito negro é resultante de sua vida pessoal, da sua história psicossocial, bem como do contexto histórico que vivenciou.

Nesse aspecto, Severino (2010) destaca que:

A escola tem como função oportunizar à criança a expansão de suas experiências, proporcionando ao aluno aprofundar o seu processo de aquisição de conhecimentos, não esquecendo, do respeito às questões culturais que cada um traz, a partir da qual se constrói a identidade dos alunos, tendo a atenção necessária no resgate de suas origens e história, respeitando os direitos humanos, e promovendo a convivência com o diferente (p. 20).

A construção da identidade negra precisa ser discutida, valorizada e reconhecida no espaço escolar. Pois todo o processo da identidade negra confronta com a realidade da nossa sociedade, enfrentando o racismo e o preconceito. Assim, de acordo com Carvalho (2012) a instituição escolar é um espaço social no qual os adolescentes compartilham significados, referências, representações e outras práticas identitárias presentes nas sociedades.

Conforme Pinto e Ferreira (2014) ao estudarmos o processo de construção da identidade da pessoa negra, é muito comum as pessoas categorizarem os indivíduos quanto às suas características raciais de maneira reducionista, baseando-se exclusivamente na cor da pele - 
classificando-os em negros ou brancos. No entanto, o que torna importante é o conhecimento do processo de como a pessoa negra se constitui no mundo, o processo de construção de sua imagem, cultura e suas formas de existir.

Nesse contexto, no Brasil, de acordo com Munanga (1999), a mestiçagem é a expressão mais popularmente utilizada para demonstrar e explicar o processo de construção de uma identidade negra, em seus aspectos raciais e culturais. Diante disso, Munanga (1999) afirma que:

O mestiço brasileiro simboliza plenamente essa ambiguidade cuja consequência na sua própria definição é fatal, num país onde ele é de início indefinido. Ele é —um e outroll, —o mesmo e o diferentell, - nem um nem outroll, - ser e não serll, -pertencer e não pertencerll. Essa indefinição social - evitada na ideologia racial norte-americana e no regime do apartheid -, conjugada com o ideário do branqueamento, dificulta tanto a sua identidade como mestiço, quanto a sua opção de identidade negra (MUNANGA, 1999,p. 126).

O conhecimento da discussão da mestiçagem tem como objetivo mediar a relação das evidências da realidade multiétnica do povo brasileiro, colaborando para o processo de valorização, reconhecimento e construção da identidade dos estudantes. Assim, de acordo com Munanga (2008) a nossa percepção de diferença situa-se no campo visual e ressalta a importância do hábito de pensar nossas identidades.

Nessa discussão da mestiçagem no espaço escolar ressalta-se a relação da teoria do "embranquecimento" no Brasil através da pintura "A Redenção de Cam" do pintor espanhol e radicado brasileiro, Modesto Brocos, de 1985, atualmente pertencente ao acervo do Museu Nacional de Belas Artes, no Rio de Janeiro. A pintura retrata a cena de quatro pessoas em frente a uma casa humilde, sendo uma senhora negra fazendo gesto de agradecimento às suas divindades, ao lado da sua filha parda, que segura seu neto branco no colo e o seu genro branco ao lado. $\mathrm{O}$ título da obra faz uma referência a Cam do livro do Gênesis da Bíblia, filho de Noé, cuja maldição feita pelo pai condenou os descendentes à cor negra e à escravidão, segundo as teorias racistas.

Para Lotierzo e Schwarcz (2013):

"A imagem é um retrato de família marcado pelas distintas gradações de cor na pele das
personagens - do marrom escuro ("negro") da avó, ao "branco" do neto e de seu pai,
passando pela mãe, morena, cuja tez adquire na tela um tom dourado. Em consonância,
o grande interesse despertado pela pintura, que recebeu a medalha de ouro naquela
Exposição Geral de Belas Artes, parece atado ao tema das uniões interraciais no Brasil e,
em especial, à sua transformação em emblema dos debates sobre o futuro de um país
marcado pela forte presença de uma população que não se define nem como negra, nem
como branca, e pelos impasses que a chamada mestiçagem trazia para uma nação que se 
pretendia, no futuro, branca, num momento de auge do pensamento racialista na esfera pública" (p. 1).

A partir de uma observação da pintura desenvolvem-se discussões como: Qual a relação da pintura com o conceito de miscigenação e da pluralidade étnica na atualidade? Como pode ser discutida a identidade negra na atualidade? Como podemos relacionar os temas atuais do racismo e do preconceito a partir das observações feitas da pintura e do seu contexto? Que outros questionamentos podem ser discutidos? Porém, para responder esses questionamentos, Trotta e Santos (2012) ressaltam que a própria identidade nacional está atravessada pela conflituosa negociação do papel da população negra na sociedade, balizada pela escravidão e pelo racismo.

Nesse sentido, a socialização no espaço escolar colabora no processo identitário, como afirma Pereira (1987):

\footnotetext{
A constituição da identidade do ser humano como expressão de grupos e categorias sociais está indissoluvelmente ligada ao processo de socialização tout-court. Daí pode-se afirmar que uma das funções da socialização é a da construção da pessoa humana dentro dos parâmetros de seu locus espacial, temporal e sociocultural, ou, numa linguagem mais filosófica, dentro de ideais ou modelo de pessoa definido pela sociedade (p. 10).
}

Dessa forma, a discussão da identidade negra torna-se um processo complexo diante das possibilidades do processo de construção, bem como de desconstrução. Pois se torna abrangente desde a sua territorialização, defora espacial, temporal e cultural. Assim, a discussão da identidade negra evidencia a sua característica holística.

De acordo com Martins e Silva (2018) a escola é o espaço onde não só aprendemos conteúdos e saberes escolares, mas também valores, hábitos, ética, bem como preconceitos raciais, de gênero, de classe, e formamos nossa identidade. Por isso a importância do ambiente escolar na formação dos jovens educandos, bem como a inclusão da discussão no currículo, com a finalidade de trazer os alunos à reflexão, ao entendimento e ao combate ao preconceito e discriminação. Assim, para Severino (2010) a escola tem como função criar oportunidades para que os alunos expressem suas experiências, propiciando o a discussão do seu processo de obtenção de conhecimentos, respeitando às questões culturais que cada um traz, a partir da qual se constrói a sua identidade, resgatando suas origens e histórias. 


\section{CONCLUSÕES}

O espaço escolar possibilita o desenvolvimento dos principais elementos de construção e pertencimento da identidade negra, como um currículo que agregue a valorização da afrodescendência e indígena, como previsto nos Parâmetros Curriculares Nacionais. O espaço escolar, através de práticas socializadoras tem a capacidade de engajar os jovens no debate e reflexão crítica para um processo de reconhecimento de uma identidade considerada às margens das oportunidades de um jovem não negro, que precisa de políticas públicas para o acesso as vagas em universidades e instituições públicas. Dessa forma, através de práticas interdisciplinares, com o uso do debate da Ciência, das Inovações, da Literatura, da Música, do Cinema e das demais áreas, o espaço escolar pode contribuir no processo de construção identitária dos jovens estudantes.

Portanto, a construção da identidade racial dos discentes tornar-se-á fundamentalmente a partir das suas interações e relações sociais no ambiente em que vive e na sociedade que faz parte. Assim, a importância do espaço escolar na construção da identidade negra permeia como esse discente se autoreconhece como integrante dessa relação, como se constituem suas dinâmicas de pertencimento ao grupo, de disseminação de sua cultura e como se estabelece a relação consigo mesmo. Dessa forma, essa construção identitária está em constante transformação e reconstrução.

Nesse sentido, o espaço escolar consiste no lugar de socialização, discussão e esclarecimentos no processo de construção das identidades dos jovens estudantes. Sendo essa construção envolvida em todo o processo educativo, podendo ocorrer manifestações de conflito, como o racismo, a segregação dos jovens e consequentemente as negações de identidades. Assim, os estereótipos ou até mesmo representações da identidade negra podem influenciar no desenvolvimento pessoal, social e educacional dos jovens. 


\section{REFERÊNCIAS}

ABREU, M. Diversidade cultura, reparação e direitos. In: DANTAS; C. V.; MATTOS, H.; ABREU. M. (Orgs.). O negro no Brasil: trajetórias e lutas em dez aulas de história. Rio de Janeiro: Objetiva, 2012. cap. 10, p. 107-112.

BASTOS, P. C. "Eu nasci branquinha": construção da identidade negra no espaço escolar, Revista Eletrônica de Educação, v. 9, n. 2, p. 615-636, 2015.

CARVALHO, Mauro. A construção das identidades no espaço escolar. Revista Reflexão e Ação, Santa Cruz do Sul, v. 20, n.1, p.209-227, jan./jun.2012.

CUNHA, J. A. Iniciação à investigação filosófica: um convite ao filosofar. 2. ed. CampinasSP: Editora Alínea, 2013. 456 p.

FAZZI, R. C. O drama racial de crianças brasileiras: socialização entre pares e preconceito. Belo Horizonte: Autêntica, 2006.

FOULCAULT, M. Em defesa da sociedade. Tradução de Maria Ermantina Galvão. São Paulo: Martins Fontes, 1999.

GIL, A. C. Métodos e técnicas de pesquisa social. 6. ed. São Paulo: Atlas, 2008.

GUIRADO, M. Diferença e alteridade: dos equívocos inevitáveis. In: Diferenças e preconceito na escola: alternativas teóricas e práticas. São Paulo: Summus, 1998.

LOTIERZO, T. H. P.; SCHWARCZ, L. K. M. Raça, gênero e projeto branqueador: "a redenção de Cam”, de Modesto Brocos. Data de mise em ligne, Samedi, n. 5, v. 28, p. 1-26, setembro, 2013.

MARTINS, K. F.; SILVA, C. S. O processo de (des)construção da identidade negra na escola: o olhar de professores e alunos em uma escola do município de Quixadá-CE. Revista da ABPN, v. 10, ed. especial, p. 215-237, maio, 208.

MIZAEL, N. C. O.; GONÇALVES, L. R. D. Construção da identidade negra na sala de aula: passando por bruxa negra e preto fudido a pretinho no poder. Itinerarius Reflections - Revista Eletrônica da Pós-Graduação em Educação, v. 11, n. 2, p. 1-21, 2015.

MUNANGA, K. Rediscutindo a mestiçagem no Brasil: Identidade nacional versus identidade negra. Belo Horizonte: Autêntica, 2008.

MUNANGA, K. Rediscutindo a mestiçagem no Brasil: identidade nacional versus identidade negra. Petrópolis: Vozes, 1999. 152 p.

OLIVEIRA, M. J. C. Construção da identidade do aluno negro no âmbito escolar. 2016. In: X Simpósio Linguagens e Identidades da/na Amazônia Sul-Ocidental; VIII Colóquio Internacional "As Amazônias, as Áfricas e as Áfricas na Pan-Amazônia". Disponível em: <revistas.ufac.br/revista/index.php/simposioufac/article/download/850/447>. Acesso em: 02 jun. 2018. 
PEREIRA, J. B. B. A criança negra: identidade étnica e socialização. São Paulo: Cadernos de Pesquisa (USP), n. 63, novembro de 1987.

PINTO, M. C. C.; FERREIRA, R. F. Relações raciais no Brasil e a construção da identidade da pessoa negra. Pesquisas e Práticas Psicossociais, v. 9, n. 2, p. 257-266, jul./dez., 2014.

SEVERINO, R. A. A formação da identidade da criança negra no contexto escolar. 2010. 47 f. Trabalho de Conclusão de Curso (Graduação em Psicologia) - Universidade do Extremo Sul Catarinense, Criciúma, 2010.

SOUZA, A. K.; GOMES, C. O. B. A construção positiva e negativa da identidade da criança e do adolescente afrodescendente no contexto escolar. Revista Brasileira de Psicologia, n. 2, n. especial, p. 73-84, 2017.

SOUZA, I. S. O resgate da identidade na travessia do movimento negro: arte, cultura e política. Doutorado em Psicologia Escolar e do Desenvolvimento Humanos, Universidade de São Paulo, São Paulo, SP, 1991.

TROTTA, F. C.; SANTOS, K. J. F. P. Respeitem meus cabelos, brancos: música, política e identidade negra. Revista Famecos, Porto Alegre, v. 19, n. 1, p. 225-248, jan./abr., 2012. 